\title{
LIBERALISMO, CENTRALISMO Y DEMOCRACIA RESTRINGIDA EN LA ARGENTINA (1880-1916)
}

\author{
EZEQUIEL GALLO
}

Antes de describir y analizar el modelo político existente en la Argentina entre c. 1880 - c. 1912 es necesario referirse a los problemas que dicho modelo intentó resolver y a las respuestas que consideró adecuadas para su solución. Los problemas que aquejaban a la Argentina hacia mediados de! siglo XIX eran de una doble naturaleza. En primer lugar, la Independencia había creado un llamativo vacio institucional que había dado lugar a la anarquía y a la guerra civil o a la dictadura personal (1). En segundo término, los hombres que a partir de 1852 intentaron la organización nacional estaban obsesionados con la pobreza material del lugar y, especialmente, con la escasez de la población en relación a la vastedad del territorio. En palabras de los más influyentes escritores de la época (Alberdi y Sarmiento, por ejemplo) la Argentina debía quebrar ese desierto de personas y actividades que era, a su vez, una de las causas generadoras del caos y de la violencia institucional (2).

Los constituyentes de 1853 encararon resueltamente la respuesta a ambos males. J. B. Alberdi, el escritor que más influyó sobre el texto constitucional, había esbozado claramente los caminos adecuados. Con respecto al segundo de los mencionados (el desierto) sus respuestas giraron alrededor del siguiente razonamiento:

\begin{abstract}
«Pero ¿cuál es la constitución que mejor conviene al desierto? la que sirve para hacerlo desaparecer... Luego este debe ser el fin político de la constitución argentina y en general de todas las constituciones de Sud-América... Es pues, esencialmente económico el fin de la política constitucional y del gobierno en América. Así, en América, gobernar es poblar» (3).
\end{abstract}

(1) La importancia del vacío institucional generado por la Independencia surge con claridad cuando se compara la situación argentina con dos paises nuevos de cierta semejanza, Australia y Chile. En Australia no hubo tal ruptura, y la evolución institucional, guiada muchas veces por la Corona, fue sumamente pacifica y contínua. En Chile, donde sí hubo ruptura, el régimen presidencialista inaugurado por Portales y consagrado por la Constitución de 1833 aseguró un largo período de estabilidad institucional. Hacia 1860, por ejemplo, ambos países se hallaban muy por delante de la Argentina en todos los niveles del acaecer social.

(2) La mejor descripción contemporánea del «desierto» se encuentra en D. F. Sarmiento, Facundo: Civilización y Barbarie (1845), Buenos Aires, 1940.

(3) Juan B. Alberdi, Bases y puntos de partida para la organización politica de la República Argentina, Buenos Aires, 1852. 
El desierto se quebraba atrayendo pobladores y capitales del exterior. La Constitución debía, por lo tanto, facilitar los medios que hicieran posible su transferencia. El medio propuesto por Alberdi, y adoptado por los constituyentes de 1853, se inscribia claramente dentro de la tradición de pensamiento liberal clásica (o, en sus propias palabras, «la gran escuela industrial de Adam Smith»):

Nuestra revolución abrazó la libertad económica, porque ella es el manantial que la ciencia reconoce a la riqueza de las naciones; porque la libertad convenía esencialmente a las necesidades de la desierta República Argentina que debe atraer con ella la población, los capitales, las industrias de que carece hasta hoy con riesgo de su independencia y libertad...» (4).

Las libertades económicas y civiles (religiosas, de asociación, de prensa, etc.) eran, pues, el medio idóneo para atraer esas corrientes de hombres y capitales. La Constitución debía establecerlas haciendo explícito que ellas regían, sin discriminación alguna, tanto para nacionales como para extranjeros. Así lo hicieron los constituyentes de 1853 y los legisladores que en décadas posteriores sancionaron las leyes complementarias (Códigos civil, comercial, penal, etc.) (5).

No se le escapaba a Alberdi que toda esta legislación sería inoperante si no se generaban paralelamente condiciones que aseguraran la paz y estabilidad institucional. En otras palabras, si no se ponía fin al círculo vicioso de guerras civiles y de tiranías personales. La solución propuesta sería aquí de naturaleza disímil a la ofrecida para solucionar el problema del desierto. Alberdi localizaba el origen de los males institucionales en la brusca y radical ruptura con el viejo orden colonial: «no se andan de un salto las edades extremas de un pueblo» (6). La solución debía, en consecuencia, rescatar parte de lo que había sido arrasado por el vendaval de la independencia. La institución de una monarquía constitucional resultaba impensable luego de décadas de retórica republicana. Bolívar había esbozado, tiempo atrás, una transacción sugestiva: «los nuevos estados de la América antes española necesitan reyes con el nombre de presidentes». Para Alberdi, la vecina república de Chile había dado el ejemplo práctico: «Chile ha resuelto el problema sin

(4) Juan B. Alberdi, Sistema económico y rentístico de la Confederación Argentina según su constitución de 1853, Buenos Aires, 1854.

(5) No hace falta señalar que hubo aspectos minoritarios no-liberales en la legislación citada. Cfr. mi la Evolución del liberalismo argentino, AIETI, Madrid (en prensa).

(6) Juan B. Alberdi Bases, op. cit. 
dinastias y sin dictaduras militares, por medio de una constitución monárquica en el fondo y republicana en la forma » (7).

La solución pasaba, entonces, por la institución de un «rey republicano», es decir, por la constitución de un Ejecutivo fuerte, enmarcado dentro de leyes generales y limitado, en cierta medida, por un sistema republicano clásico de división de poderes. El esquema resultante se complementaba con una preferencia valorativa por el sistema representativo y con un gesto simpático hacia las tradiciones federales surgidas durante las guerras civiles. La Constitución Argentina de 1853 fue, por lo tanto, una curiosa mezcla de dos precedentes: se proclamó republicana, representativa y federal como su antecedente estadounidense, del cual se tomó, también, todo lo referente a las garantías de las libertades civiles. Pero a diferencia del precedente norteamericano otorgó al Ejecutivo nacional herramientas mucho más fuertes de mando, especialmente en relación a los estados provinciales. Esta última característica fue influida directamente por la Constitución chilena de 1833.

Uno de los aspectos más influyentes del pensamiento de Alberdi fue su percepción acerca del ritmo con el cual debía implementarse este conjunto complejo de normas institucionales. En este sentido distinguió entre lo que denominó la «república posible» y la «república verdadera». Durante la primera proponía la combinación entre una vigencia irrestricta e inmediata de libertades civiles y una implementación gradual ( $\mathrm{y}$, por lo tanto, restringida al comienzo) de libertades políticas:

«No participo del fanatismo inexperimentado, cuando no hipócrita, que pide libertades políticas a manos llenas que sólo saben emplearlas para crear sus propios tiranos. Pero deseo ilimitadas... para nuestros pueblos las libertades civiles, a cuyo número pertenecen las libertades económicas de adquirir, enajenar, trabajar, navegar, comerciar, transitar, y ejercer toda industria lícita» (8).

Al postular esta combinación Alberdi creia tender hacia dos metas: 1) la ya mencionada de quebrar el desierto y 2) a través del trabajo cotidiano y de la inmigración romper con los hábitos y tradiciones negativos generados por una legislación civil restrictiva y por décadas de enfrentamientos armados. El doble mecanismo (civil y político) de la república posible generaría el cambio de tradiciones y costumbres que facilitaria el tránsito hacia la repú-

(7) Alberdi admiraba la solución política chilena, pero era muy crítico de la legislación social de ese pais, a la que consideraba muy restrictiva de las libertades civiles.

(8) Juan B. Alberdi, Sistema económico y rentístico, op. cit. La interpretación más ajustada del pensamiento de Alberdi puede verse en N. Botana, La tradición republicana. Alberdi, Sarmiento y las ideas politicas de su tiempo, Buenos Aires, 1984. 
blica verdadera donde convivirán plenamente las libertades civiles y las politicas.

El esquema institucional esbozado en 1853 no fue de fácil implementación. Al mismo tiempo que se sancionaba la Constitución estalló una nueva guerra inter-provincial que se extendió hasta 1862. A partir de esta fecha se inició un ciclo de 18 años que asistió a un gradual afianzamiento de los poderes nacionales, pero que estuvo signado por diversos alzamientos provinciales que conspiraron contra el clima de paz y estabilidad buscado por los constituyentes de 1853. Esos alzamientos se iniciaron las más de las veces en oposición a la consolidación de los poderes nacionales; en otras versiones (especialmente en la provincia de Buenos Aires) en defensa del principio de la representación democrática. Todas estas rebeliones fracasaron pero introdujeron un clima de inestabilidad y violencia que conspiraba contra la entrada de capitales e inmigrantes extranjeros.

La última de las grandes rebeliones provinciales tuvo lugar en 1880, y fue liberada por la poderosa provincia de Buenos Aires. En esta ocasión las tropas nacionales obtuvieron una categórica victoria sobre las milicias de la provincia rebelde. De inmediato el Congreso Nacional aprobó una serie de leyes encaminadas a otorgar aún más atribuciones al poder central, debilitando la posición relativa de las distintas provincias y, muy especialmente, la de Buenos Aires. Estas medidas incluyen la federalización de la ciudad de Buenos Aires, la eliminación de las milicias provinciales, la prohibición de emitir moneda a las autoridades provinciales, el otorgamiento de mayores atribuciones a la justicia nacional, etc., etc. También la Iglesia Católica vio disminuida sus atribuciones al disponerse que la educación primaria y los registros civiles pasaban a depender del gobierno nacional. Estas medidas pusieron fin a los enfrentamientos armados inter-provinciales, afianzaron definitivamente la unidad nacional y posibilitaron la supremacía indiscutida de los poderes nacionales. Recién entonces, podría decirse, quedaron establecidas las bases institucionales de la «república posible» sugerida por Alberdi y por los constituyentes de 1853.

\section{CAMBIOS ECONÓMICOS Y SOCIALES}

Antes de analizar las características centrales del régimen instaurado en 1880 (que se prolongaría hasta 1916) es necesaria una breve referencia a los cambios ocurridos en la sociedad argentina a partir de las reformas institucionales de la década del ochenta. La relativa estabilidad política que caracterizó al período 1880-1916 posibilitó el desencadenamiento de un «boom» económico de larga duración y de características excepcionales. La emergencia de un pujante sector capitalista en el sector rural estimuló un fuerte 
ingreso de personas y capitales provenientes de Europa y desató procesos similares de expansión en el comercio, el transporte y la manufactura urbana. El cuadro n. ${ }^{\circ} 1$ ilustra la evolución de los indicadores más significativos de este proceso.

\section{CUADRO N. ${ }^{\circ} 1$ \\ Evolución económica argentina (c. 1870 - c. 1914)}

\begin{tabular}{|c|c|c|}
\hline & c. 1870 & c. 1914 \\
\hline Población & 1.800 .000 & 7.800 .000 \\
\hline $\begin{array}{l}\text { Comercio exterior } \\
\text { (millones de pesos oro) }\end{array}$ & 74 & 1.000 .000 \\
\hline Ferrocarriles (km.) & 700 & 32.000 \\
\hline $\begin{array}{l}\text { Hectáreas sembradas co } \\
\text { cereales, lino y alfalfa }\end{array}$ & 200.000 & 30.000 .000 \\
\hline
\end{tabular}

Capital invertido en industria

(millones de pesos oro)

Resulta obvio señalar que un proceso de esta magnitud produjo, a su vez, alteraciones significativas en la estructura social del país. La más significativa de ellas fue el ingreso de cerca de 3.500 .000 de inmigrantes europeos (el $70 \%$ proveniente de Italia y España). En un plazo de 40 años se radicó en la Argentina una población que representaba casi el doble de la que existía en el punto de partida (1870). Ningún otro país registró una relación semejante entre población original e ingreso de inmigrantes. Este incremento notable de la población fue acompañado por otros cambios sociales de igual significación: un rápido proceso de urbanización y de mejoramiento de los niveles educativos y una apreciable diversificación de la estructura social como consecuencia de tasas muy altas de movilidad social. Esto último produjo la emergencia de una vasta clase media en las ciudades y en la región cerealera, al mismo tiempo que el crecimiento manufacturero posibilitaba el surgimiento de un proletariado urbano que tuvo una presencia importante en núcleos urbanos como Buenos Aires y Rosario. La culminación lógica de todos estos procesos rápidos de cambio social fue la aparición de una serie de organiza- 
ciones que aspiraron a representar los intereses de los nuevos sectores sociales: sindicatos obreros, centrales empresarias, asociaciones de inmigrantes, etc., etc. (10).

Resulta, por lo tanto, importante tener en cuenta que el proceso político de la época se hizo dentro del marco de una realidad insospechada para los contemporáneos a los sucesos. La asimilación de millones de extranjeros y la emergencia constante de nuevos sectores tuvo que ser procesada por dirigentes políticos que habian sido formados en épocas muy disímiles. La bonanza económica amortiguó en buena medida el impacto de los distintos conflictos sociales que aparecieron por aquellos años, pero las agrupaciones políticas, viejas y nuevas, tuvieron grandes dificultades para canalizar dentro de sus organizaciones a las nuevas tendencias que emergían en ese cambiante mundo social.

\section{LA REPÚBLICA POSIBLE}

El debate político entre c. 1850 y c. 1880 giró principalmente alrededor de los caminos adecuados para unificar el país (terminar con los conflictos inter-regionales) y consolidar una autoridad nacional estable. En este debate se enfrentaron dos tradiciones diferentes, una centralista y otra autonomista, ambas cobijadas, paradójicamente, bajo una retórica federal común. Hacia 1880 , como ya quedó insinuado, el triunfo de la tendencia centralista aparecía como irreversible. Las palabras con las que Leandro Alem se opuso a la federalización de Buenos Aires (1880) resuenan hoy como el dolorido adiós a una vieja tradición de la política argentina:

«Es una tendencia natural del poder a extender sus atribuciones, a dilatar su esfera de acción y a engrandecerse en todo sentido, y si ya observamos ahora como se arrojan sombras sobre la autonomía de algunas provincias... ¿qué no sucederá cuando se sienta [la autoridad nacional] poderosa y sin control alguno en sus procedimientos? Creo firmemente que la suerte de la República Argentina que-

(9) Para un análisis de la evolución económica argentina cfr. R. Cortés Conde «The Growth of the Argentine Economy. 1870-1914», y E. Gallo, «Argentina: Society and Politics 1880-1916»; ambos en L. Bethell (ed.), The Cambridge History of Latin America c. 1870-1930, V, Cambridge, 1986.

(10) E. Gallo, op. cit. 
dará librada a la voluntad y a las pasiones del jefe del Ejecutivo Nacional» (11).

Alem sería más adelante (1891) el fundador del principal partido de oposición al régimen vigente, la Unión Cívica Radical (UCR). No hay indicador más contundente del triunfo de la tendencia centralista que la evolución del nuevo partido. Con la muerte de Alem, y su reemplazo por Hipólito Irigoyen, el radicalismo adoptó rápidamente una postura centralista igual, y en ocasiones mayor, que la sustentada por los más prominentes políticos del régimen vigente (12).

El programa centralizador apareció claramente delineado en el discurso inaugural al Congreso (1880) del Presidente Roca, el más influyente político del nuevo Partido Autonomista Nacional (PAN).

«Parece que fuéramos un pueblo recién caído a la vida nacional pues tenéis que legislar sobre todo aquello que constituye los atributos, los medios y el poder de la Nación, tan grande era la falta de una capital permanente para la República» (13).

Y así se legisló durante la década del ochenta. La unidad nacional y la relativa estabilidad institucional se alcanzaron, en consecuencia, al costo de una gran erosión de los viejos principios de autonomía federativa. Fue sobre estas bases institucionales que el PAN estructuró el sistema político que le permitió regir durante 36 años los destinos de la nueva República.

Ese sistema político funcionó, con pocas excepciones, con una fuerte supremacia del titular del Poder Ejecutivo Nacional. La Constitución, se ha señalado, había creado una institución presidencial fuerte y le habia otorgado un mandato relativamente largo ( 6 años). Pero le había puesto, también, un límite severo al prohibir la reelección inmediata del mandatario de turno (de-

(11) L. N. Alem, «Discurso sobre la Federalización de Buenos Aires (1880)», en Obras Parlamentarias, III, La Plata, 1940. Así como Alberdi representó la tendencia conservadora del pensamiento liberal, Alem fue el representante de la corriente más radical de esa ideología política. Su liberalismo surge claramente en este otro pasaje del mismo discurso: «Si, gobernad lo menos posible, porque mientras menos gobierno tiene el hombre, más avanza la libertad, más gobierno propio tiene y más fortalece su iniciativa..."

(12) Irigoyen sostuvo esta posición desde los comienzos de su carrera política. En el debate parlamentario sobre la federalización de Buenos Aires votó a favor de la posición oficial y en contra de las tesis sotenidas por Alem.

(13) J. Roca, «Mensaje presidencial de 1881», en Mensajes de Roca de 1880 a 1886, Buenos Aires, 1966. Roca fue dos veces Presidente de la República (1880-86 y 1898-1904) y, para muchos, el verdadero artífice del régimen inaugurado en 1880 . Cfr. mi «El Roquismo» en Todo es Historia, n. ${ }^{\circ} 100$, Buenos Aires, 1975. 
bía transcurrir un período completo para que pudiera volver a presentar su candidatura). La elección de un sucesor leal a la situación vigente se convirtió de esa manera en el engranaje crucial para la continuidad del PAN en el poder (14).

El mecanismo que posibilitaba el control de la sucesión presidencial descansaba en las relaciones establecidas entre el Presidente dé la República y los gobernadores de provincia. Eran estos últimos los que debian asegurar que los miembros del Colegio Electoral respondieran a los deseos presidenciales. Para lograr este propósito se generó un sistema de premios y castigos que consistió básicamente en la elección del gobernador saliente al senado de la Nación, y en caso de rebeldía, en la utilización de la intervención federal, esa poderosa herramienta centralizadora que la Constitución otorgó al Presidente de la República (15). Un prestigioso político del régimen, O. Magnas$\mathrm{co}$, ilustró sin eufemismos los propósitos de la intervención federal:

«Las intervenciones federales en esta tierra han sido invariablemente decretadas con uno de estos dos fines: o para ahogar una influencia o para restablecerla, o para levantar un gobierno local que garantice la situación doméstica al Ejecutivo o para derrocar un gobierno local desafecto a la política central».(16).

Este mecanismo simple descansaba, sin embargo, sobre engranajes bastante más complejos. La Constitución, como se ha dicho, facilitaba la manipulación presidencial, pero estipulaba condiciones rígidas para que pudiera ser ejercida. Entre ellas figuraba la realización de elecciones periódicas (en promedio cada dos años) en distintos niveles (nacional, municipal y provincial) y para diversos cargos (presidente, gobernador, senadores, diputados, intendentes y concejales). Está de más señalar que esas elecciones debían ser ganadas para permitir la continuidad del régimen imperante.

Los medios que permitían la victoria electoral del oficialismo fueron diversos y variaron tanto en el tiempo como en el espacio. Una caracterización genérica, necesariamente estereotipada e incompleta, apuntaría a las siguientes características. En primer lugar, a una muy baja participación electoral. En el caso argentino este fenómeno se acentuaba por la escasa participación

(14) Esta descripción está inspirada en N. Botana, El Orden Conservador. La política argentina entre 1830 y 1916, Buenos Aires, 1977. La elección presidencial en Argentina es indirecta, como en los Estados Unidos, a través de un Colegio Electoral.

(15) Cfr. H. Sommariva, Historia de las intervenciones federales en las provincias, II, Buenos Aires, 1929.

(16) O. Magnasco citado por J. Irazusta en El tránsito del siglo XIX al XX, Buenos Aires, 1975, p. 169. 
de los extranjeros que en las regiones más pobladas del país representaban de un $40 \%$ a un $50 \%$ de la población total (17). Pero la participación era muy baja, también, entre los nativos con derecho a voto (varones mayores de 18 años). En líneas generales votaba entre el $10 \%$ y el $15 \%$ de quienes tenían derecho al sufragio; en algunos casos este porcentaje podría alcanzar entre el $25 \%$ y el $30 \%$. La participación electoral era, por otra parte, mucho más alta en las zonas rurales que en las urbanas, y más baja entre los sectores medios y altos (18).

El éxito en las elecciones dependía, en consecuencia, de los apoyos que pudieran obtenerse entre la parte de la población que concurría a los comicios. Estos apoyos se lograban a través de un intrincado y variable sistema de relaciones que tenía en el vértice al gobernador y la dirección provincial y en la base a los llamados caudillos (caciques) de distrito. Eran estos últimos los que reunían a las distintas clientelas electorales. Las relaciones entre la dirección provincial y los caudillos distaban de ser sencillas y descansaban en contraprestaciones reciprocas cuyo quebrantamiento introducía grados importantes de inestabilidad. La misma situación es detectable cuando se analizan las relaciones entre esos caudillos y sus clientelas electorales.

Este mecanismo funcionó pacíficamente en la mayoría de las ocasiones, en buena medida porque la apatía de la población hacía innecesaria la apelación a la violencia o al fraude. Estos últimos hechos ocurrían cuando la oposición movilizaba sus huestes para la contienda electoral, o, en forma más dramática, cuando convocaba a la sublevación cívico-militar. En ambas ocasiones la lealtad de las clientelas políticas era un factor decisivo y, en rigor, parte del éxito del régimen descansó en su habilidad para retener esa leal$\operatorname{tad}(19)$.

El sistema de democracia restringida que caracterizó al régimen convivió con las características más liberales de la «república posible». Una amplia libertad de prensa, de asociación y de reunión permitió el surgimiento de una serie de grupos y asociaciones que expresaron puntos de vista de distinta orientación ideológica. La disciplina partidaria en el Congreso se aplicaba solamente en casos donde se jugaba la continuidad del régimen (intervenciones federales, por ejemplo), lo cual dejaba una amplia variedad de temas (económicos, sociales y políticos) donde los legisladores podían expresarse libremente. El Poder Judicial, además, funcionó con independencia y eficiencia

(17) Las leyes argentinas exigian sólo dos años de residencia en el pais para solicitar carta de ciudadania. Los hijos de los inmigrantes eran ciudadanos por el solo hecho de nacer en la Argentina.

(18) Cfr. mi ya citada «Argentina: Politics and Society. 1880-1916», en L. Bethell (ed.), loc. cit.

(19) E. Gallo, «El Roquismo», op. cit. 
asegurando en alguna medida la vigencia de las libertades civiles. La contraposición entre estas libertades civiles y las restricciones electorales fue, con el tiempo, haciendo que estas últimas aparecieran como más anacrónicas e irritantes (20).

La descripción del funcionamiento del sistema político ofrecida hasta aquí no resultará, creo yo, demasiado novedosa para quienes conozcan regímenes similares en otros países europeos y latinoamericanos. La convivencia de libertades civiles con baja participación y fraude electoral no fue una característica original o distintiva de la realidad política argentina. Pero en otras latitudes esta característica convivió con la alternancia en el poder de grupos políticos antagónicos. Este aspecto brilló por su ausencia en la escena política argentina, a pesar de que los principales contendientes concordaban en aspectos importantes de la política gubernamental (educacionales, sociales, educativos, relaciones internacionales, etc.) (21).

La explicación de este fenómeno crucial no puede descansar solamente en el análisis de las instituciones vigentes, por más que el centralismo no facilitó, en mi opinión, en los hábitos y tradiciones que dominaron desde la Independencia la vida política local. La Argentina vivió desde 1810 siete décadas de guerras casi contínuas $y$, algunas veces, devastadoras. La superación gradual de esta situación a partir de 1880 no desarraigó enteramente a una mentalidad configurada por el largo período de enfrentamientos armad os. La pacificación progresiva del país dejó casi intacta una percepción de la vida política que hizo de la exclusión del adversario uno de sus pilares centrales. Una exclusión que no solamente se reflejaba en el más alto nivel nacional sino que recorría todos los demás engranajes del intrincado mecanismo descrito anteriormente. El triunfo de la oposición era percibido y presentado como el retorno a épocas de caos, anarquía y guerra civil, y por lo tanto, como un retroceso inaceptable (22).

La actitud exclusivista del régimen tuvo su contrapartida en una oposición que apeló con reiteración a la sublevación armada, vista como la legítima respuesta a una situación que exagerada, pero reiteradamente, se describía como tiránica. La retórica emergente de civismo republicano condujo,

(20) El Poder Judicial fue elogiado aún por acerbos opositores al régimen. Cfr. A. Belin Sarmiento, Una República Muerta (1891), Buenos Aires, 1970.

(21) El Partido Socialista, por ejemplo, se adhirió con más ortodoxia que el oficialismo a los principios de libre comercio y patrón oro. Lo mismo puede decirse de la mayoría de los dirigentes de la UCR. Cfr. E. Gallo: «Agrarian expansion and Industrial development in Argentina» en R. Carr (ed.) Latin American Affairs, Oxford, 1970.

(22) Estos aspectos los he analizado en «Traditions and Political Styles in Argentina», Argentina - US. Forum, Maryland, 1979. 
asimismo, al rechazo de todo diálogo o acuerdo con los dirigentes moderados y conciliadores del oficialismo. Nada ilustra mejor este estado de ánimo que el prestigio creciente de la palabra Intransigencia, considerada por buena parte de la oposición como atributo moral irrenunciable para el hombre público. Alem ilustró bien esta actitud de rechazo al acuerdo y la conciliación cuando sostuvo que «en la política, como en todo, se hace lo que se debe y cuando lo único que se puede hacer es malo, no se hace nada» (23).

El ya mencionado reemplazo de Alem por Irigoyen en la jefatura de UCR modificó muchas cosas, pero dejó en pie el rechazo al acuerdo y el recurso a la conspiración (ahora despojada de la retórica de republicanismo cívico) como las armas más legítimas de la contienda política. El círculo vicioso creado por la conjunción de exclusivismo y de intransigencia fue sagazmente expuesto por Carlos Pellegrini, líder, desde comienzos de siglo, de la facción moderada del oficialismo:

«Vivimos girando en círculo funesto de recriminaciones recíprocas y de males comunes. Los unos proclaman que mientras haya gobiernos personales y opresores ha de haber revoluciones; y los otros contestan que mientras haya revoluciones han de existir gobiernos de fuerza y de represión. Todos están en la verdad, o más bien, todos están en el error» (24).

La situación descrita produjo consecuencias que no por esperables deban ser omitidas en este relato. En primer lugar, con una oposición excluida o auto-excluida, la marcha política del país dependió especialmente de las pujas de facciones que tenían lugar dentro del partido oficialista (PAN). En segundo término, redujo considerablemente el espacio a disposición de los hombres moderados y conciliadores que existían en ambos bandos de la vida política. El tránsito de la república «posible» a la «verdadera» estuvo, pues, trabado contínuamente por la tenaz persistencia de tradiciones y hábitos que introdujeron una gran rigidez en el sistema político.

\section{HACIA LA REPÚBLICA VERDADERA}

¿Cómo quebrar el círculo vicioso expuesto por Carlos Pellegrini? No está de más recordar aquí algunos aspectos salientes del debate político. La discusión nunca fue sobre la superioridad del sistema democrático elegido por la Constitución y reiterado por la legislación posterior. Esta legislación desde muy temprano había definido al cuerpo electoral en forma amplia para la época

(23) L. N. Alem, Mensaje y Destino, Buenos Aires, 1955, VII, p. 233.

(24) C. Pellegrini, Obras completas, Buenos Aires, 1941, IV, p. 419. 
(varones nativos y nacionalizados mayores de 18 años). La legislación argentina no establecía restricciones de propiedad ni excluyó a los analfabetos, aún en épocas que éstos representaban cerca del $80 \%$ de la población (c. 1870). Lo que se discutía era sobre los medios y oportunidad, mediante los cuales debian desterrarse los vicios que distorsionaron en la práctica la legislación vigente. Se ha subrayado el vocablo oportunidad para indicar que, en buena medida, ésta era una discusión sobre el ritmo que debía tener la reforma política. Por razones de espacio, y con el riesgo de estereotipar en demasia la realidad, trataré de ilustrar el problema con el pensamiento político de dos personajes significativos de la época: Julio Roca, fundador del régimen vigente a partir de 1880, y Leandro Alem, creador del principal partido de oposición a partir de 1891.

Julio Roca era un político austero y parco, que dominó como pocos el arte de enhebrar alianzas regionales y nacionales. Su visión política estuvo fuertemente influida por los aspectos más conservadores del pensamiento de Alberdi. Su vida pública estuvo fuertemente condicionada por su obsesión con la consolidación de instituciones nacionales que siempre percibió como inestables y frágiles. Creía que estas últimas características eran la resultante de una mentalidad demasiado propensa a la sedición y a la anarquía. La respuesta a estos riesgos las encontró en la fuerte centralización del poder y en la implementación de un ritmo gradual y cauteloso de reforma política. Su impaciencia con las demandas de cambios inmediatos está constantemente reflejada en sus discursos políticos:

«No es confiadas en el entusiasmo de la plaza pública ni en los arrebatos del momento, que las naciones conservan su independencia e integridad, sino con la paz interior, el respeto al principio de autoridad y el acatamiento a la Constitución y a las leyes" (25).

En 1914, ya retirado de la vida política, expuso una vez más esta percepción de la vida política argentina. En esta ocasión consideró que la reforma electoral de 1912 constituía un salto al vacío que pondría en peligro la estabilidad alcanzada en las últimas dos décadas. En la que sería su última declaración pública Roca reiteró viejas obsesiones y justificó sin reservas al régimen político inaugurado en 1880 , cuyo principal objetivo fue:

«Defender dos cosas esenciales, siempre en peligro: el principio de autoridad y la unión nacional contra las fuerzas latentes, pero siempre en asedio de la rebelión, de la anarquía, de la sedición. Pero no

(25) Julio A. Roca, en su ya citado mensaje presidencial de 1881. 
conviene forjarse ilusiones sobre la solidez de nuestra organización, ni de la unidad nacional... La anarquía no es planta que desaparezca en el espacio de medio siglo en sociedades mal cimentadas como las nuestras» (26).

Si Roca representó a la vertiente conservadora del pensamiento liberal, Leandro Alem fue el expositor más claro de la vertiente radical de esa corriente de ideas. Federalista y anti-centralista ortodoxo, pensaba que los males políticos de la época debían solucionarse en forma drástica y radical, y que, en consecuencia, los acuerdos y transacciones sólo beneficiaban al oficialismo. Exponente claro de una actitud racionalista, su visión política estuvo condicionada por un rechazo a la tradición como guía para la acción pública:

«...es un malísimo sistema tomar la tradición como razón suprema y decisiva para la solución de estos problemas de la filosofía política. Es de la escuela conservadora y aún puedo llamarla estacionaria, que se levanta todavía al frente de la escuela racional y liberal» (27).

La postura racionalista y radical de Alem fundamentó y justificó la rebelión cívico militar como instrumento legítimo para reestablecer derechos constitucionales que se consideraban conculcados. Las grandes sublevaciones de 1890 y de 1893 lideradas por Alem y la UCR tuvieron esa retórica justificatoria, y lo mismo se argumentó para rechazar el Acuerdo político propuesto por el oficialismo en 1891 (28).

Hubo, desde luego, posiciones intermedias entre las de Roca y Alem, pero aún las propuestas más moderadas y concialiadoras no pudieron despojarse enteramente de los aspectos más rígidos del pensamiento de ambos líderes políticos. El clima de recelos mutuos generados por estas cosmovisiones explica, en buena medida, la demora en avanzar hacia una reforma gradual de las prácticas políticas, especialmente entre 1890 y 1904 cuando las circunstancias resultaron propicias para soluciones de esa naturaleza.

Hacia 1905 la situación política tuvo un vuelco importante. Ese año el gobierno desbarató con relativa facilidad una conspiración militar organizada por los radicales. Pareció entonces, que se había dado el golpe final a las intervenciones del Ejército en la vida política. Durante las dos décadas siguientes

(26) Reportaje periodístico a Roca en M. de Vedia y Mitre, Como los vi yo, Buenos Aires, 1922, p. 60 ss.

(27) L. Alem en el ya citado discurso sobre la federalización de Buenos Aires.

(28) Cfr. E. Gallo: «Un quinquenio difícil: Las presidencias de C. Pellegrini y R. Sáenz Peña (1890-1895)" en G. Ferrari y E. Gallo (ed.), La Argentina del Ochenta al Centenario, Buenos Aires, 1980. 
el temor a la sublevación militar dejó de ser un factor de peso en la percepción del futuro institucional. Esta dosis de mayor tranquilidad se reforzó con la bonanza y el optimismo económico que caracterizó a la década que precedió al estallido de la primera guerra mundial. La conjunción de ambos factores creó un clima de tranquilidad favorable a la consideración de una reforma electoral que coronase el edificio institucional propuesto por la Constitución.

Estos dos factores hubiesen sido insuficientes si, al mismo tiempo, no se hubiesen producido cambios significativos en la conducción del partido oficialista. El largo período del predominio de Roca llegaba a su término, y la conducción del Partido Autonomista Nacional pasaba a manos de las facciones que se habían opuesto a su liderazgo. Roca fue desplazado, desde luego, con los mismos instrumentos con los cuales había manejado al partido oficial. La diferencia estribaba en que la oposición a Roca había convertido a la reforma electoral en el tema prioritario de su acción política. Estos sectores impusieron en 1910 a Roque Sáenz Peña (un viejo reformista) como Presidente de la República, quien no tuvo inconveniente dos años después en propiciar y sancionar la ley electoral que lleva su nombre (29).

El saneamiento de prácticas electorales (la «pureza del sufragio», como se decía entonces) había sido una aspiración explícita de todos los actores políticos. La nueva conducción oficialista consideraba, además, que la oportunidad era propicia para su implementación. Para muchos, la reforma era necesaria para poner a la vida política a tono con la modernización que estaba teniendo lugar en el mundo social. Una sociedad moderna requería, se decía, un partido conservador moderno y no una coalición de caudillos locales anacrónicos. La competencia electoral revertiria, además, la atonía polítjca que resultaba del estilo personalista y cerrado del viejo sistema. $Y$, finalmente, permitiría, según los reformistas, la incorporación definitiva y pacífica al sistema de los partidos de la oposición.

El argumento «reformista» fue aceptado por la mayoría del partido oficial. Contribuyeron a eso el optimismo reinante por los indudables progresos del país, y la fuerte sospecha de muchos políticos oficialistas de que el PAN era la mayoría natural del país. El debate parlamentario en que se aprobó la ley electoral muestra claramente la convicción del oficialismo acerca de su victoria en los comicios presidenciales que tendrían lugar en 1916 (31).

Los comicios de 1916 arrojaron un resultado opuesto al esperado por

(29) Ibidem. Roque Sáenz Peña fue candidato a la presidencia de 1891 por una facción disidente del oficialismo que tomó el nombre de Partido Modernista. La reforma de las prácticas electorales fue el argumento central de su campaña electoral.

(30) Para el debate parlamentario en el cual se aprobó la ley Sáenz Peña ver N. Botana, El Orden Conservador, capítulos VIII y IX. 
los dirigentes del régimen. En ellos triunfó la Unión Cívica Radical que consagró a Hipólito Irigoyen como Presidente de la República. Tres factores explican, a mi entender, lo que un año antes hubiera sido considerado como un resultado sorpresivo 1) el partido oficialista había sido desde su origen una coalición inestable de facciones provinciales. Mantenerlo unido había sido siempre la obra de persolidades muy fuertes (Roca, Pellegrini, Sáenz Peña, por ejemplo). Todas ellas habian desaparecido de la escena política en 1916. 2) Muchos caudillos provinciales resistieron la idea de un partido moderno que tendía a minimizar su función. El resultado de estos dos factores fue que el oficialismo concurrió a los comicios dividido en dos candidaturas. 3) La ley electoral de 1912 provocó un aumento insospechado de la participación electoral (del $20 \%$ a casi el $80 \%$ del padrón). Este aumento fue particularmente notable en las zonas urbanas donde la maquinaria electoral del régimen fue siempre bastante débil. Efectivamente, la oposición triunfó en los centros urbanos y el oficialismo en las zonas rurales. En la ciudad de Buenos Aires se anotó una fuerte presencia del nuevo Partido Socialista (31).

La elección de 1916 fue ganada por un margen muy estrecho, tanto que estuvo a punto de ser revertido en el Colegio Electoral. Los cálculos optimistas del oficialismo fueron, de todas maneras, refutados por los hechos. En 1916, empero, el tránsito de la «república posible» a la «república verdadera» parecía concluido en forma pacífica y establecido sobre bases sólidas y permanentes.

\section{CONCLUSIÓN}

Un observador ubicado en 1920, o aún en 1928, hubiera analizado, quizás, el relato anterior como la historia de un éxito. A la par de los muy significativos avances realizados en el campo económico y social, la República había evolucionado, lenta y trabajosamente, hacia la unión nacional y la consolidación de sus instituciones. La Constitución de 1853, las reformas del ochenta y la ley electoral de 1912 fueron los hitos cruciales de ese proceso. La última de ellas posibilitó el acceso pacífico de la oposición al poder y amplió espectacularmente los niveles de participación ciudadana. Más aún, como se señaló anteriormente, el Ejército, a partir de 1905, parecía haberse encaminado definitivamente en una actitud de subordinación al poder político.

Desde una atalaya ubicada en 1931, luego de la quiebra del orden cons-

(31) Cfr. E. Gallo y S. Sigal: «La formación de los partidós políticos contemporáneos: La Unión Cívica Radical (1890-1916)» en Desarrollo Económico, Buenos Aires, III, 1963. Entre 1912 y 1916 el Partido Socialista triunfó en dos elecciones parlamentarias en la ciudad de Buenos Aires (1913 y 1914). Tuvo, sin embargo, escaso peso electoral con pocas excepciones, en el resto del país. 
titucional y democrático en 1930, la observación anterior podría aparecer como injustificadamente optimista. El problema es que cualquier explicación que analice los sucesos de 1930 en función de lo ocurrido antes de 1916 corre el riesgo de ser excesivamente conjetural. Ciertamente muchas cosas nuevas ocurrieron entre 1916 y 1930 como para establecer cadenas causales contínuas a través de diez y ocho años. La más importante de ellas fue el giro dramático operado en el mundo de las ideas después de la terminación de la primera guerra mundial. La evolución argentina entre 1853 y 1912 había transcurrido en un mundo que valoraba altamente al constitucionalismo liberal y democrático. No hace falta recordar que esto cambió drásticamente en el período entre las dos guerras mundiales. La experiencia de democracia ampliada se inició, pues, en la Argentina en un momento en que las alternativas hostiles al liberalismo y a la democracia adquirian creciente influencia, especialmente en el continente europeo.

Pero hubo, también, circunstancias locales que condujeron a la quiebra de 1930. La más importante, a mi entender, está relacionada con la persistencia de hábitos políticos que no fueron modificadas por las reformas institucionales mencionadas anteriormente. La excesiva centralización y la escasa atención a la división de poderes (con la excepción del Poder Judicial) contribuyeron a consolidar hábitos de intolerancia y rigidez poco aptos para dar estabilidad a la vida democrática. La reforma de 1912, por ejemplo, fue un exitoso intento de modificar prácticas electorales viciosas, pero no alteró nada en los demás aspectos de la vida institucional. El radicalismo en el poder (especialmente durante las dos presidencias de Irigoyen) agravó aún más la situación. La intervención federal fue usada generosamente para derribar situaciones provinciales adversas, el papel del Congreso fue minimizado por un Ejecutivo absorbente y, finalmente, se volvió a politizar a las fuerzas armadas. Una política de exclusión debilita lealtades indispensables para el mantenimiento de un régimen, especialmente en tiempos de crisis. El golpe de estado de 1920 fue estimulado por grupos minoritarios de tendencia antidemocrática, pero contó con el apoyo entusiasta de la gran mayoría de las fuerzas de oposición democrática. Sin este apoyo, como se vio poco después, el golpe hubiera fracasado rotundamente (32).

(32) Los grupos de inspiración corporativista que encabezaron el golpe, fueron desplazados rápidamente. A partir de entonces (y hasta 1943) el país fue gobernado por una retórica constitucional y democrática pero con retorno al fraude electoral. Para el gobierno de irigoyen Cfr. A. M. Mustapic, "Conflictos institucionales durante el primer gobierno radical: 1916-1922", Desarrollo Económico, XXIV, Buenos Aires, 1984. Para la politización del Ejército en la segunda presidencia de Irigoyen cfr. R. Potash, The Army and Politics in Argentina, 1928-1945. Irigoyen to Peron, Stanford, 1969. 